\title{
GMR
}

\section{Genetic diversity analysis of Capparis spinosa L. populations by using ISSR markers}

\author{
C. Liu ${ }^{1 *}$, G.P. Xue ${ }^{1,2 *}$, B. Cheng ${ }^{1}$, X. Wang ${ }^{1}$, J. He ${ }^{1}$, G.H. Liu ${ }^{1}$ and W.J. Yang ${ }^{1}$ \\ ${ }^{1}$ Xinjiang Institute of Materia Medica, WLMQ, Xinjiang Province, China \\ ${ }^{2}$ Shool of Pharmacy, Shihezi University, Shihezi, Xinjiang Province, China \\ *These authors contributed equally to this study. \\ Corresponding authors: C. Liu / W.J. Yang \\ E-mail: liu_chong02@163.com / wilfred3106@163.com
}

Genet. Mol. Res. 14 (4): 16476-16483 (2015)

Received July 15, 2015

Accepted September 20, 2015

Published December 9, 2015

DOI http://dx.doi.org/10.4238/2015.December.9.19

ABSTRACT. Capparis spinosa L. is an important medicinal species in the Xinjiang Province of China. Ten natural populations of C. spinosa from 3 locations in North, Central, and South Xinjiang were studied using morphological trait inter simple sequence repeat (ISSR) molecular markers to assess the genetic diversity and population structure. In this study, the 10 ISSR primers produced 313 amplified DNA fragments, with $52 \%$ of fragments being polymorphic. Unweighted pair-group method with arithmetic average (UPGMA) cluster analysis indicated that 10 C. spinosa populations were clustered into 3 geographically distinct groups. The Nei gene of $C$. spinosa populations in different regions had Diversity and Shannon's information index ranges of $0.1312-0.2001$ and $0.1004-0.1875$, respectively. The 362 markers were used to construct the dendrogram based on the UPGMA cluster analysis. The dendrogram indicated that 10 populations of $C$. spinosa were clustered into 3 geographically distinct groups. The results showed these genotypes have high genetic diversity, and can be used for an alternative breeding program.

Key words: Capparis spinosa L.; Inter-simple sequence repeat; Genetic diversity 


\section{INTRODUCTION}

Capparis spinosa L. belongs to the family Capparidaceae. The geographical origin of $C$. spinosa is disputed, with supporters claiming origins in China, India, and central Asian. The plant grows in desert regions of China, including the Gobi. The flower buds of $C$. spinosa have long been employed in culinary and medicinal practices; the buds can be used as a flavoring in cooking or as a diuretic, antihypertensive, poultice and tonic in traditional medicine (Baytop, 1984). In China, C. spinosa is mainly distributed in the Xinjiang province. Its fruits have been used in traditional medicine to treat rheumatic arthritis and gout (Fu et al., 2007).

Understanding the level of genetic diversity and the population genetic structure is important for medicinal plant species, because this allows the establishment of effective and efficient conservation practices and can guide choices for their genetic management. Nowadays, it is possible to use several molecular methods to analyze the genetic variability in plant species. One of them, inter-simple sequence repeat polymorphisms (ISSR), have been successfully used for genetic analysis of medicinal plants, as they require no prior knowledge of the DNA sequence and are universally applicable as dominant markers (Sa et al., 2011) for rapid exploratory work on new species. Furthermore, ISSRs have been demonstrated to be useful for the analysis of inter- and/or intra-specific genetic diversity in different Gentianaceae species (Ge et al., 2005; Zhang et al., 2007; Yang et al., 2011; Zheng et al., 2011).

Genetic variation within and among natural populations is crucial for the long-term survival of a species. Especially for medicinal species, an accurate estimate of the genetic variation among or within its populations could be helpful to address its status (Brown et al., 1996; Dávila, et al., 1998; Ge et al., 1999; Camacho et al., 2001), and provide fundamental information in designing conservation programs (Neigel, 2002). In this study, for the first time the population-level genetic diversity of $C$. spinosa was analyzed using ISSR markers to determine the genetic differentiation between populations from different regions in Xinjiang. It will provide invaluable information for future C. spinosa L. conservation and management programs.

\section{MATERIAL AND METHODS}

\section{Plant materials}

Ten populations were sampled from 3 geographically separate locations in North, Central, and South Xinjiang (Figure 1). At each location, samples were randomly collected from 8-10 C. spinosa individuals from 10 sites (accessions) separated by a distance of approximately $10 \mathrm{~m}$ (Table 1).

\section{DNA extraction}

Genomic DNA was extracted from young leaves following the CTAB (Cetyl Trimethyl Ammonium Bromide) Method. DNA concentration and quality was assessed on $1 \%$ agarose gel using a NanoDrop spectrophotometer (NanoDrop Technologies, Wilmington, DE, USA).

\section{ISSR amplifications}

ISSR markers were produced by PCR using the genomic DNA and ISSR primers. PCRs 
were conducted using 22 primers (Table 2) to characterize the 94 Capparis spinosa L. samples. The 20- $\mu \mathrm{L}$ mixture contained $10 \mathrm{ng}$ template DNA, $2.0 \mu \mathrm{L}$ 10X PCR buffer, $1.0 \mu \mathrm{L}(0.1 \mathrm{mM}) \mathrm{dNTPs}$ (Tiangen, Beijing, China), 2\% formamide, $100 \mathrm{nM}$ each primer, $1.5 \mathrm{U}$ Taq polymerase (Tiangen, Beijing, China), and double-distilled water. Amplifications were performed using a BioRAD C1000 Thermal Cycler (Applied Biosystems,California, America) with the following PCR program: 5 min initial denaturing at $94^{\circ} \mathrm{C}, 40$ cycles of $94^{\circ} \mathrm{C}$ for $45 \mathrm{~s}, 1 \mathrm{~min}$ for annealing at the primer-specific melting temperature, and $72^{\circ} \mathrm{C}$ for $90 \mathrm{~s}$, followed by a final extension of $5 \mathrm{~min}$ at $72^{\circ} \mathrm{C}$. First, the PCR products were analyzed by electrophoresis on $1.0 \%$ agarose gel with $0.5 \mathrm{X}$ TBE buffer. All products were analyzed on $1.5 \%(\mathrm{p} / \mathrm{v})$ agarose gels stained with loading buffer. A 100-bp DNA ladder was used as a size marker.

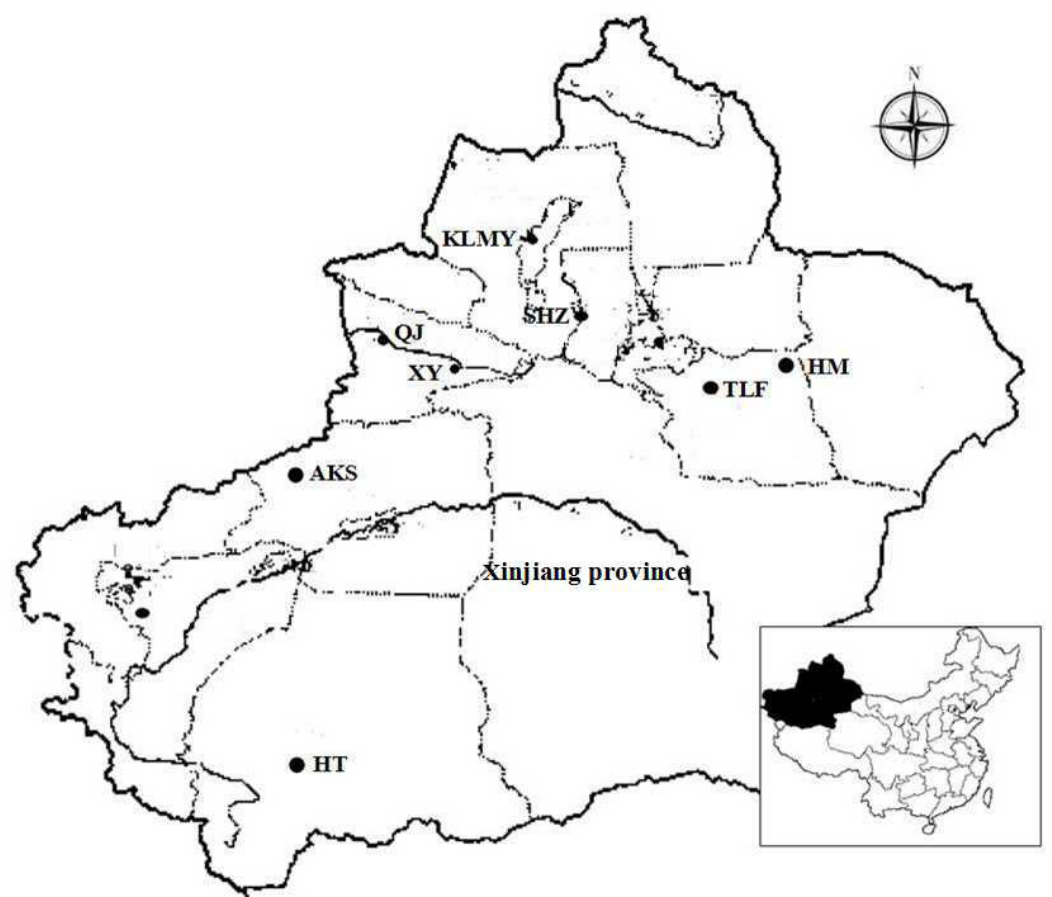

Figure 1. Map showing the distributions of Capparis spinosa and locations of ten populations sampled from Xinjiang.

Table 1. Populations of Capparis spinosa surveyed.

\begin{tabular}{|c|c|c|c|c|}
\hline Location & Population name & Longitude & Latitude & Altitude $(\mathrm{m})$ \\
\hline Urumqi & WLMQ & $87^{\circ} 33^{\prime} 23^{\prime \prime} \mathrm{E}$ & $43^{\circ} 47^{\prime} 18^{\prime \prime} \mathrm{N}$ & 890.6 \\
\hline Qianjin Pastureland & QJ & $80^{\circ} 87^{\prime} 97^{\prime \prime} \mathrm{E}$ & $44^{\circ} 05^{\prime} 45^{\prime \prime} \mathrm{N}$ & 812.3 \\
\hline Kelamayi & KLMY & $84^{\circ} 45^{\prime} 35^{\prime \prime} \mathrm{E}$ & $44^{\circ} 55^{\prime} 88^{\prime} \mathrm{N}$ & 412.1 \\
\hline Shihezi & $\mathrm{SHZ}$ & $85^{\circ} 89^{\prime} 68^{\prime \prime} \mathrm{E}$ & $44^{\circ} 73^{\prime} 09^{\prime \prime} \mathrm{N}$ & 490.7 \\
\hline Xinyuan & $X Y$ & $83^{\circ} 25^{\prime} 23^{\prime \prime} \mathrm{E}$ & $43^{\circ} 18^{\prime} 19^{\prime \prime} \mathrm{N}$ & 816.5 \\
\hline hami & $\mathrm{HM}$ & $81^{\circ} 32^{\prime} 84^{\prime \prime} \mathrm{E}$ & $43^{\circ} 92^{\prime} 41^{\prime \prime} \mathrm{N}$ & 790.3 \\
\hline Tulufan & TLF & $89^{\circ} 11^{\prime} 60^{\prime \prime} \mathrm{E}$ & $42^{\circ} 51^{\prime} 63^{\prime \prime} \mathrm{N}$ & 75.5 \\
\hline Akesu & AKS & $75^{\circ} 89^{\prime} 72^{\prime \prime} \mathrm{E}$ & $39^{\circ} 89^{\prime} 37^{\prime \prime} \mathrm{N}$ & 1088.2 \\
\hline Kashi & KS & $76^{\circ} 02^{\prime} 13^{\prime \prime} \mathrm{E}$ & $39^{\circ} 75^{\prime} 11^{\prime \prime} \mathrm{N}$ & 1283.3 \\
\hline Hetian & $\mathrm{HT}$ & $75^{\circ} 80^{\prime} 29^{\prime \prime} \mathrm{E}$ & $39^{\circ} 53^{\prime} 08^{\prime \prime} \mathrm{N}$ & 1275.4 \\
\hline
\end{tabular}




\section{Data analysis}

The percentage of polymorphic loci $(P)$, effective numbers of alleles $\left(N_{E}\right)$, gene diversity (expected heterozygosity, $H_{E}$ ), Shannon's diversity index (I), and unbiased genetic distances according to Nei (1978), were calculated using PopGene32 (Yeh et al., 1999) for both markers. ISSRs are dominant markers, with each band representing the phenotype at a single biallelic locus. Only bands that could be unambiguously scored were used in the analysis. ISSR amplified bands were scored for band presence (1) or absence (0), and a binary qualitative data matrix was formed. The obtained genetic distance matrix was used to perform the cluster analysis and construct the unweighted pair-group method with arithmetic average (UPGMA) dendrogram using Power Marker software (Liu and Muse, 2005).

The third approach used the program Structure, version 2.3.4 (Pritchard et al., 2000), which identifies clusters of related individuals from multilocus genotypes. Individuals were assigned (probabilistically) to a cluster or jointly to two or more clusters if their haplotypes indicated that they are admixed; each cluster is characterized by a set of allele frequencies at each locus (Pritchard et al., 2000). To choose the best number of genetic clusters (K), multiple values were tested (from 1 to 7 ) using a length of burning period of 10,000 steps and 10 repetitions. The results were analyzed using the on-line tool, Structure Harvester (Earl et al., 2012), which implements the method of Evanno et al., 2005 to detect the true number of clusters in a non-homogeneous sample of individuals.

\section{RESULTS}

The amplification of the ISSR fragments in the 94 individuals, analyzed with ten primers, yielded 313 unambiguous and reproducible electrophoretic bands ranging from 5 to 15 bands for each of the primers, with an average of 9.3 bands per primer (Table 2). The estimates of genetic diversity in $C$. spinosa demonstrated a remarkable level of genetic variation among populations (PPL $=76.13 \%$, Nei's gene diversity $\left(H_{E}\right)=0.2878$ ); the average genetic diversity at the population level was $H_{E}=0.1686$. The percentages of polymorphic loci for a single population ranged from $20.64 \%(X Y)$ to $47.87 \%$ (TLF) with an average of $26.96 \%$ in the Tianshan Mountain populations (Table 3). According to the source of grow into WLMQ, QJ, KLMY, SHZ, XY and HM, TLF and AKS, KS, HT, The three group of Xinjiang, detection of genetic diversity of each area level. The results showed that the Nei gene of $C$. spinosa populations in different regions had a diversity $(H)$ and Shannon's information index (I) range, respectively, of 0.1312-0.2001 and 0.1004-0.2855. The highest $H_{E}$ and I value were for TLF populations; the lowest values were for the WLMQ population. The average Shannon's indices showed a strong correlation (Pearson's $r=0.999$ ) with gene diversity. The values of gene diversity and Shannon's index showed a similar trend to that of the percentages of polymorphic loci.

\section{Cluster analysis of $C$. spinosa populations}

The neighbor-joining cladogram based on these genetic distances clustered the populations according to their geographical regions of origin (Figure 2). Three clusters of populations of $C$. spinosa from the Tianshan Mountains were obtained in three cladograms with high bootstrap values; the first group consisted of 5 populations from WLMQ, QJ, KLMY and SHZ, 
all located in the northern part of the region. The second cluster was formed by AKS, KS and HT, the three populations located in the southern region. The third cluster included HM and TLF, the two populations located in the eastern portion of the sampled region. As can be seen from the clustering results, the geographic distribution of the 10 populations and the germplasm, which had a shorter geographical distance, tended to be in the same category. In general, the $10 \mathrm{C}$. spinosa populations had small genetic distance and high genetic similarity.

\begin{tabular}{|c|c|c|c|c|}
\hline Primer & Sequence (5'-3') & Polymorphic amplicons & Polymorphism \% & $\mathrm{Ta}\left({ }^{\circ} \mathrm{C}\right)$ \\
\hline UBC807 & AGA GAG AGA GAG AGA GT & 11 & 91.2 & 55.2 \\
\hline UBC808 & AGA GAG AGA GAG AGA GC & 9 & 100.0 & 57.2 \\
\hline UBC811 & GAG AGA GAG AGA GAG AC & 6 & 100.0 & 54.2 \\
\hline UBC813 & СтС тст СТС ТСт СтС тT & 8 & 100.0 & 54.2 \\
\hline UBC815 & СТС ТСТ СТС ТСТ СТС TG & 8 & 100.0 & 50.1 \\
\hline UBC826 & ACA CAC ACA CAC ACA CC & 8 & 100.0 & 55.3 \\
\hline UBC844 & СTC TCT СTC TCT СTC TRC & 11 & 100.0 & 53.4 \\
\hline UBC888 & BDB CAC ACA CAC ACA CA & 11 & 100.0 & 55.0 \\
\hline UBC897 & CCG ACT CGA GNN NNN NAT GTG G & 11 & 100.0 & 56.8 \\
\hline UBC899 & CAT GGT GTT GGT CAT TGT TCC A & 10 & 100.0 & 56.8 \\
\hline
\end{tabular}

$R=(A, G), B=(C, G, T), N=(A, G, C, T), D=(A, G, T)$.

Table 3. Genetic variation in populations of Capparis spinosa detected by ISSR markers.

\begin{tabular}{|c|c|c|c|c|c|c|c|c|}
\hline Geographic region & Population name & Sample size & $\mathrm{N}$ & PPL & $N_{\mathrm{A}}$ & $N_{E}$ & $H_{\mathrm{E}}$ & I \\
\hline \multirow[t]{5}{*}{ North Xinjiang (north of Tianshan Mountains) } & WLMQ & 10 & 23 & 22.55 & 1.4225 & 1.223 & 0.1312 & 0.1004 \\
\hline & QJ & 10 & 24 & 26.81 & 1.4681 & 1.2875 & 0.1649 & 0.1453 \\
\hline & KLMY & 10 & 31 & 23.19 & 1.5319 & 1.25 & 0.1533 & 0.1385 \\
\hline & $\mathrm{SHZ}$ & 10 & 33 & 22.13 & 1.5213 & 1.2955 & 0.1735 & 0.1615 \\
\hline & $X Y$ & 8 & 29 & 20.64 & 1.6064 & 1.3397 & 0.1549 & 0.1017 \\
\hline \multirow[t]{2}{*}{ East Xinjiang (The Eastern of Tianshan Mountains) } & HM & 9 & 52 & 42.13 & 1.5213 & 1.3091 & 0.1783 & 0.2675 \\
\hline & TLF & 11 & 64 & 47.87 & 1.4787 & 1.2591 & 0.2001 & 0.2855 \\
\hline \multirow[t]{6}{*}{ South Xinjiang (The Southern of Tianshan Mountains) } & AKS & 10 & 30 & 26.81 & 1.4681 & 1.2744 & 0.1594 & 0.1992 \\
\hline & KS & 8 & 34 & 29.57 & 1.5957 & 1.3136 & 0.1884 & 0.1869 \\
\hline & $\mathrm{HT}$ & 8 & 42 & 32.87 & 1.4787 & 1.3231 & 0.1817 & 0.1769 \\
\hline & Mean values & & 36.2 & 29.56 & 1.509 & 1.288 & 0.1686 & 0.1763 \\
\hline & Group & & & 76.13 & 1.967 & 1.5091 & 0.2878 & 0.3614 \\
\hline & Total & 94 & 362 & & & & & \\
\hline
\end{tabular}

$\mathrm{N}=$ number of polymorphic loci; $\mathrm{PPL}=$ percentage of polymorphic loci; $N_{\mathrm{A}}=$ observed mean number of alleles per locus; $N_{E}=$ effective mean number of alleles per locus; $I=$ Shannon's information index; $H_{E}=$ Nei's gene diversity.

The analysis of individual multilocus genotypes of the 94 samples using the Structure algorithm showed the best clustering solution for $K=3$. Figure 3 shows that all individuals of the Tianshan Mountain C. Spinosa populations were assigned to the three remaining clusters: i) individuals from TLF and HM (eastern populations), ii) individuals from AKS, KS and HT (southern populations), and iii) individuals from XY, QJ, KLMY, SHZ and WLMQ (northern populations). Individuals showing probabilities of assignment to more than one cluster were observed in all of the Tianshan Mountains populations, revealing that there has been some gene flow between clusters. The proportions of individuals that have at least a $5 \%$ probability of assignment to another cluster were $23.1 \%$ for the eastern population group, $29.2 \%$ for the northern population group, and $10.1 \%$ for the southern population group. 


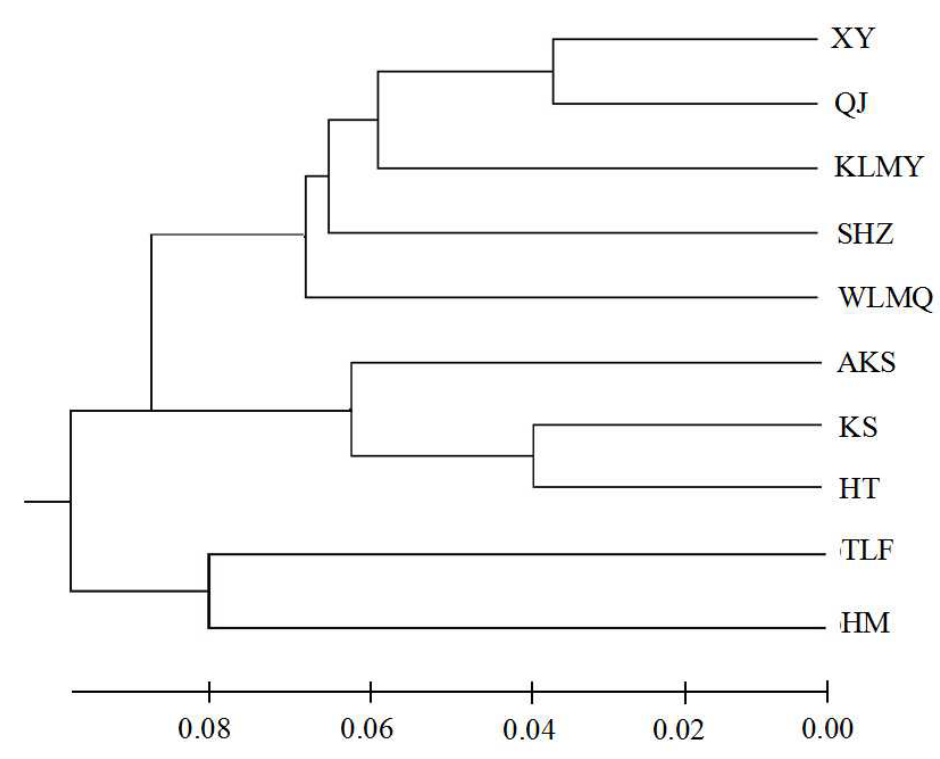

Figure 2. UPGMA clustering of ten Capparis spinosa populations based on Nei 's genetic distance.

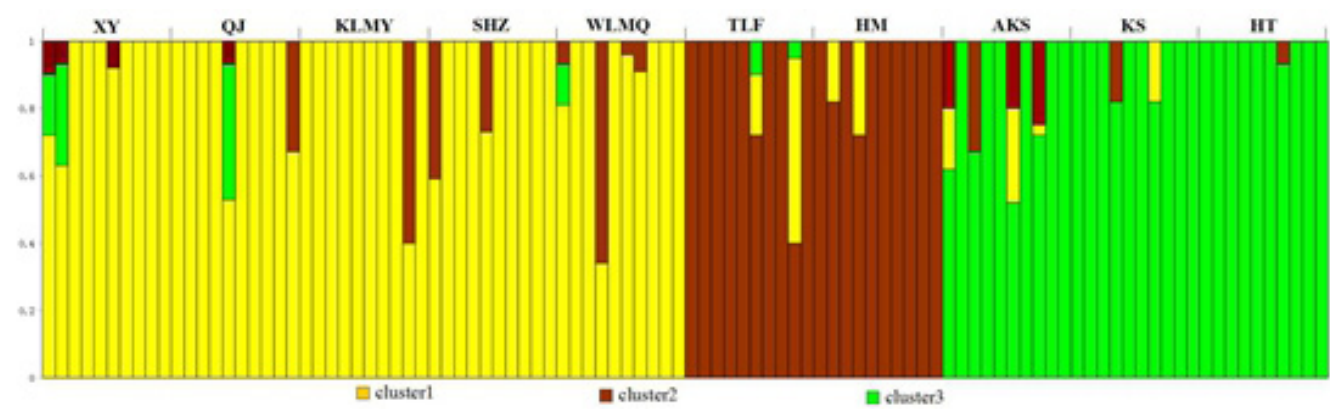

Figure 3. Genetic relationships among the 10 Capparis spinosa populations estimated using the STRUCTURE program based on ISSR data. The model with $\mathrm{K}=3$ showed the highest $\Delta \mathrm{K}$ value.

\section{DISCUSSION}

C. spinosa is a perennial shrub with a patchy distribution. The populations are often located in distant mountain ranges and are isolated from each other by the Gobi or other deserts. In this sturdy, we report the first study of genetic polymorphism in C. spinosa populations using ISSR markers. The high levels of variation among $C$. spinosa populations may be mainly due to gene flow $\mathrm{Nm}$ as low as $0.7093\left(\mathrm{Nm}=\left(1-G_{\mathrm{ST}}\right) / 2 G_{\mathrm{ST}}\right)$ When $\mathrm{Nm}$ values are less than 1 , it can lead to greater genetic variation in populations because genetic homogenization does not occur readily. In addition, the $G_{\mathrm{ST}}$ value of $C$. spinosa populations was 0.4134 which is within the range of $G_{\mathrm{ST}}$ values of vegetatively propagated plants $(0.410-0.510)$ (Oscar et al.,2014). Asexual (clonal) reproduction 
had a similar effect on the genetic structure of plants as strict self-pollination, which would cause large genetic variation among individuals as well as among populations, leading to a significant genetic differentiation among populations. To identify whether $C$. spinosa were vegetatively propagated plants or not, tools other than $G_{S T}$ values should be used to investigate the reproductive origin. The first cluster, which contains populations WLMQ, QJ, KLMY, SHZ, and XY, had larger genetic similarity and medium-sized fruit. The remaining populations, with the exception of KS and HT, formed another cluster and had large fruit. Genetic differences may have been reflected in the phenotype of fruits; further research of $C$. spinosa genetic variation should be carried out in combination with morphological analyses. C. spinosa was discovered in TLF population range and is most widely used as a medicine. From this study, genetic analysis can be utilized to determine suitable growing conditions for planting and provide the basis for resource protection of $C$. spinosa and similar medicinal plants.

\title{
ACKNOWLEDGMENTS
}

\author{
Research supported by the National Natural Science Foundation of XinJiang \\ (\#2013211A109).
}

\section{REFERENCES}

Baytop T (1999). Therapy with medicinal plants in Turkey (past and present), Nobel Tip Kitabevleri, Istanbul, $2: 142$.

Brown SM and Kresovich S (1996). Genome mapping in plants (Paterson AH, ed.). Clandes, New York, 85-93.

Camacho JC and Liston A (2001). Population structure and genetic diversity of Botrychium pumicola (Ophioglossaceae) based on inter-simple sequence repeats (ISSR). Am. J. Bot. 81: 965-972.

Dávila JA, Sánchez de la Hoz MO, Loarce Y and Ferrer E (1998). The use of random amplified microsatellite polymorphic DNA and coefficients of parentage to determine genetic relationships in barley. Genome 41: 477-486.

Earl D and von Holdt B (2012). STRUCTURE HARVESTER: A website and program for visualizing STRUCTURE output and implementing the Evanno method. Conserv. Genet. Resour. 4: 359-361.

Evanno G, Regnaut S and Goudet, J (2005). Detecting the number of clusters of individuals using the software STRUCTURE: A simulation study. Mol. Ecol. 14: 2611-2620.

Fu J, Huang H, Liu J, Pi R, et al. (2007). Tanshinone IIA protects cardiac myocytes against oxidative stress-triggered damage and apoptosis. Eur. J. Pharmacol. 568: 213-221.

Ge XJ and Sun M (1999). Reproductive biology and genetic diversity of a cryptoviviparous mangrove Aegiceras corniculatum (Myrtinaceae) using allozyme and inter-simple sequence repeat (ISSR) analysis. Mol. Ecol. 8: 2061-2069.

Ge XJ, Zhang LB, Yuan YM, Hao G, et al. (2005). Strong genetic differentiation of the east-Himalayan Megacodon stylophorus (Gentianaceae) detected by inter-simple sequence repeats (ISSR). Biodivers. Conserv. 14: 849-861.

Liu KJ and Muse SV (2005). PowerMarker: an integrated analysis environment for genetic marker analysis. Bioinformatics 21: 2128-2129.

Nei M (1978). Estimation of average heterozygosity and genetic distance from a small number of individuals. Genetics 89 : 583-590.

Neigel JE (2002). Is FST obsolete? Conserv. Genet. 3: 167-173.

Oscar GL, Carlos P, Zsuzsanna G, et al. (2014). Genetic variation of the endangered Gentiana lutea L. var. aurantiaca (Gentianaceae) in populations from the Northwest Iberian Peninsula. Int. J. Mol. Sci. 15: 10052-10066.

Pritchard, JK, Stephens M and Donnelly P (2000). Inference of population structure using multilocus genotype data. Genetics 155: 945-959.

Sa O, Pereira JA and Baptista P (2011). Optimization of DNA extraction for RAPD and ISSR analysis of Arbutus unedo L. leaves. Int. J. Mol. Sci. 12: 4156-4164.

Yang LC, Zhou GY and Chen GC (2011). Genetic diversity and population structure of Swertia tetraptera (Gentianaceae), an endemic species of Qinghai-Tibetan plateau. Biochem. Syst. Ecol. 39: 302-308.

Yeh F, Boyle T, Rongcai Y and Ye Z (1999). Popgene. Version 1.31. Microsoft Window-Based Freeware for Population Genetic Analysis. 
Zhang XL, Yuan YM and Ge XJ (2007). Genetic structure and differentiation of Gentiana atuntsiensis WW Smith and G. striolata TN Ho (Gentianaceae) as revealed by ISSR markers. Bot. J. Linn. Soc. 154: 225-232.

Zheng P, Zhang K and Wang Z (2011). Genetic diversity and gentiopicroside content of four Gentiana species in China revealed by ISSR and HPLC methods. Biochem. Syst. Ecol. 39: 704-710. 